doi: 10.4183/aeb.2019.182

\title{
MINIMALLY INVASIVE PARATHYROIDECTOMY FOR PRIMARY HYPERPARATHYROIDISM
}

\author{
M. Urkan¹, Y.S. Peker ${ }^{1, *}$, E. Ozturk² \\ ${ }^{1}$ University of Medical Sciences Gulhane Training and Research Hospital - General Surgery, \\ ${ }^{2}$ Erkan Ozturk Breat and Thyroid Clinic, Ankara, Turkey
}

\begin{abstract}
Context. Primary hyperparathyroidism (PHPT), characterized by the inappropriate secretion of parathyroid hormone $(\mathrm{PTH})$ with respect to the extracellular calcium concentration. Curative treatment of PHPT is surgery and bilateral neck exploration has been replaced by minimally invasive parathyroidectomy (MIP), with the advanced imaging technologies combined with radio-guided occult lesion localization (ROLL).

Objectives. The present study analyzes the MIP data from 45 patients who underwent surgery for parathyroid adenoma and debates if MIP is a feasible technique for the treatment of PHPT.

Design. The study presents the MIP excision data of 45 hyperparathyroidism patients with a 58-month follow up period.

Results. Forty-five operations were performed for 48 parathyroid adenomas. The mean duration of operation was 22.7 (12-55) minutes. Mean follow-up was 14.2 (626) months. All patients had normal postoperative calcium levels and PTH levels were normal in the follow-up period, except for one persistent hyperparathyroidism.

Conclusions. ROLL-guided MIP is a feasible technique for parathyroid surgery and reduces surgeon based failure. It also provides the widespread application of parathyroid surgery by decreasing the need for specific experience.
\end{abstract}

Key words: Hyperparathyroidism, Minimal Invasive Parathyroidectomy, Parathyroid Adenoma.

\section{INTRODUCTION}

Primary hyperparathyroidism (PHPT) is a condition characterized by the inappropriate secretion of parathyroid hormone (PTH) with hypercalcemia (1). PHPT mostly affects individuals between the fifth and seventh decades with a greater prevalence among women (2). Of all cases, $75 \%-85 \%$ are single adenomas; the remaining cases consist of multiple adenomas, hyperplastic glands, and carcinomas.
The aim of parathyroid surgery is not only to excise the atypical parathyroid glands, but also to keep the normal parathyroid glands to achieve eucalcemia and localization of the abnormal gland is important for a successful surgical treatment.

Bilateral neck exploration was a prominent method of PHPT surgery in the past. It offers the advantages of several imaging technologies, such as high-resolution neck ultrasonography (US) and $99^{\mathrm{m}} \mathrm{Tc}$ sestamibi scintigraphy (MIBI scan). These technologies have allowed surgeons to do minimally invasive parathyroidectomy (MIP) especially in cases of single abnormal gland (3). Moreover, many cases and studies have reported that MIP provides reduced operation time, length of stay and hospital costs $(4,5)$. Furthermore, these studies showed that the "focused on one point" surgical approach has had fewer cases of permanent hypocalcemia with treatment results $(95 \%)$ similar to extended exploration (6-8). MIP also provides more successful results than bilateral neck exploration. A recent study studying 10 years result of MIP by Walsh et al. concluded that MIP applied to PHPT patients had a postoperative success rate of $98.6 \%$ which is better than bilateral neck exploration (9).

In addition to US and MIBI scan, intraoperative parathyroid hormone assay with needle aspirate of the suspicious lesions is another prominent technique. SPECT magnetic resonance imaging, positron emission tomography, and selective venous sampling are other guidance tools for determining unusual glands (10). They are mainly recommended for patients with persistent or recurrent PHPT, in addition to negative scintigraphy and US studies (1).

The studies comparing imaging techniques of parathyroid glands at PHPT patients debates the role of computed tomography, magnetic resonance imaging, positron emission tomography, selective venous sampling, US and MIBI scan. Computerized tomography and positron emission tomography have a negative effect 
as high radiation exposure. Beside even 4D computerized did not provide an improvement in initial cure rate at the surgical treatment of PHPT patients (11). Selective venous sampling is accepted as a successful localization technique for the pathological parathyroid gland, but it is debated for being an invasive technique (12). US, magnetic resonance imaging and MIBI scan are the most applied imaging techniques for pathological parathyroid glands. The sequence is from the simple and cheapest to the complex and expensive one as listed above. Combined application of these techniques is also feasible.

The radio-guided occult lesion localization (ROLL) technique since has become a standard for several breast cancer units all over the world which has been used for many other non-palpable lesions, such as axillary nodal recurrent lesions, non-palpable recurrent thyroid malignancies and finally for parathyroid adenomas $(13,14)$. The volume of parathyroid adenoma seems to be related with the preoperative PTH level but small volume primary hyperparathyroid lesions leaded to invention of new surgical approaches (15). The use of ROLL for patients with parathyroid adenomas located in any neck compartment is a technically safe and effective method. It has been associated with a higher prevalence of safe surgical margins, improved cosmetic outcome, and reduced postoperative pain, in addition to reduced excisional volume and more accurate lesion centricity within the surgical specimen $(16,17)$.

The present study analyzes the MIP data from 45 patients who underwent surgery for parathyroid adenoma diagnosed biochemically and localized with either US, MIBI scan or both.

\section{MATERIALS AND METHODS}

We retrospectively reviewed patients with PHPT who underwent MIP at the Gulhane Training and Research Hospital between May 2012 and March 2017. Hyperparathyroidism was detected as hypercalcemia with suitably elevated PTH levels, low serum phosphate $(\mathrm{P})$ levels, and normal renal function. In total, 45 patients ( 25 males and 20 females; mean age 47.8 years) who underwent MIP with ROLL guidance for parathyroid adenoma.

Preoperative localization studies of all patients were done by using high-resolution US (General Electric Logiq E9, USA). For suspicious lesions MIBI scan was applied with $0.3 \mathrm{mCi} 99^{\mathrm{m}} \mathrm{Tc}$-sestamibi. Images were taken at 20 minutes and 3 hours after injection. Localization of adenoma is noted manually by neck mapping.

MIP was applied to all patients and operations were performed under general anesthesia. Adenomas that were marked with the ROLL technique preoperatively were searched and localized intraoperatively over the skin with the guidance of a gamma probe (Crystal CXS-SGO2, Crystal GmbH, Germany). Directly afterwards, a small horizontal incision was made according to the hottest spots shown by the gamma probe, and the deep cervical space was entered by splitting the strap muscles. The gamma probe then was used to locate the adenoma to define the optimal surgical dissection. The removed specimen was analyzed by frozen-section. Intraoperatively $20^{\text {th }}$ minute after excision PTH level is controlled. Wound drain was not used and all patients were taken into a long-term follow-up.

Postoperative complications, pre-postoperative serum calcium and PTH levels, size of adenoma, duration of operation were noted and evaluated.

\section{RESULTS}

Forty-five operations were performed for 48 adenomas. Three patients had two adenomas. The female/male ratio was $4 / 5$ ( 20 female, 25 male), and the mean age was 47.8 ( $\min 18$ - $\max 82)$ years. Mean serum calcium and PTH levels were $11.5 \mathrm{mg} / \mathrm{dL}$ and $395.5 \mathrm{pg} /$ $\mathrm{mL}$ in preoperative period. Thirty-four patients were evaluated with MIBI scan for US suspicious lesions; and 31 were positive and 3 were negative on MIBI scan. Because of the high PTH and Ca levels, 3 US suspicious and MIBI negative lesions were also excised, which were finally diagnosed as parathyroid adenoma. The mean time from incision to excision of the adenoma was 22.7 minutes, length of stay was 1.5 days and follow-up duration was 14.2 months (Table 1).

In the preoperative period, all ROLL-guided localized lesions were measured by gamma probe for radioactive activity. After incision of the skin, modified mini-Kocher incision is done at the highest count point; higher ROLL activity rates (1,920-16,821 counts/ $\mathrm{sec}$ ) were recorded as a result of removing the skin barrier. Seven patients had undergone neck operation (thyroidectomy and parathyroidectomy) previously. After excision of the lesions, the success of excision is confirmed also by reduced radioactivity. The most trustworthy technique to confirm is histopathological examination of the excised specimen. However, Amza et al. stated that the most accurate results are obtained by measuring the postoperative early hormone levels 
Table 1. Data set of minimal invasive parathyroidectomy applied patients (Normal range for PTH levels: $10-65 \mathrm{pg} / \mathrm{mL}$. Normal range for calcium levels: $8.5-10.1 \mathrm{mg} / \mathrm{dL}$ )

\begin{tabular}{|c|c|c|c|}
\hline & Mean & Min & Max \\
\hline Age (Year) & 47.8 & 18.0 & 82.0 \\
\hline Length of stay (Day) & 1.5 & 1.0 & 4.0 \\
\hline Duration of operation (Min) & 22.7 & 52.0 & 12.0 \\
\hline Serum calcium (Preoperative) & 11.5 & 10.5 & 13.2 \\
\hline Serum PTH (Preoperative), pg/mL & 395.5 & 78.2 & 3307.8 \\
\hline Serum PTH (Postoperative $20^{\text {th }} \mathrm{min}$ ), $\mathrm{pg} / \mathrm{mL}$ & 35.1 & 5.7 & 310.1 \\
\hline Serum calcium (Postoperative $1^{\text {st }}$ day) & 9.1 & 6.5 & 10.8 \\
\hline Serum PTH (Postoperative $1^{\text {st }}$ day), $\mathrm{pg} / \mathrm{mL}$ & 24.4 & 2.5 & 70.2 \\
\hline Serum calcium (Postoperative $6^{\text {th }}$ month) & 9.2 & 8.5 & 10.1 \\
\hline Serum PTH (Postoperative $6^{\text {th }}$ month), pg/mL & 38.8 & 10.5 & 65.3 \\
\hline
\end{tabular}

Table 2. Postoperative complications in parathyroidectomy patients after ROLL guided MIP

\begin{tabular}{lc}
\hline Complication & n \\
\hline Transient hypocalcemia & 8 \\
Transient hypercalcemia & 3 \\
Transient hypoparathyroidemia & 12 \\
Transient hyperparathyroidemia & 3 \\
Persistent hyperparathyroidemia & 1 \\
Local wound complications & 2 \\
\hline
\end{tabular}

combined with pathological examination (18).

Regarding postoperative complications of ROLL-guided MIP, no patient had recurrent temporary or permanent laryngeal nerve injury symptoms such as dyspnea and hoarseness. Postoperative PTH levels of all patients included in the study were in the normal range, except for one persistent minimal hyperparathyroidemia. Although patients had postoperative early hyper-hypocalcemia, calcium levels of the patients were normal during follow-up. No recurrent disease and no hungry-bone were detected during follow-up period.

\section{DISCUSSION}

The prevalence of PHPT is estimated as 3 per 1,000 overall and 21 per 1,000 in women in Europe (19). As a result of increased disease rates and improvement in radiological and laboratory evaluation, the number of surgical excisions for PHPT has also increased.

PHPT is more common in females; however, the female/male ratio is $4: 5$ in our study, which is just the reverse. The probable reason for this is that the hospital in which the study took place is a militarybased hospital and the male population exceeds the female population. In our study, the mean age was 47.84 and the expected age for patients with PHPT is the fifth to seventh decade (2). The reason for our data being almost in agreement is again because of the young soldier population that our hospital serves.

MIBI scan, which is one of the advances for localizing the pathological parathyroid gland debated above, has been introduced for the diagnosis of parathyroid adenomas and it has begun to be used widely as an imaging technique for preoperative localization. However, MIBI scan is also known to have lower sensitivity for small adenomas weighing $<500 \mathrm{mg}$, especially in the presence of multiple gland pathology. Furthermore, MIBI scan is not parathyroid tissue specific. Any tissue or cell that is rich in mitochondria can uptake $99^{\mathrm{m}} \mathrm{Tc}$ and cause false positive results (20). In addition, P-glycoprotein or MDR-related protein expression is known to have an important role in false negative results of parathyroid MIBI scan (21).

The combination of US and MIBI scan is used for diagnosing the abnormal glands preoperatively with $91 \%$ and $94 \%$ sensitivity rates, respectively (22). We have diagnosed 34 patients with the combined technique and 11 patients with US only. Even the 3 of the MIBI scans applied patients were negative for parathyroid adenoma localization, MIP was applied to US suspicious lesions. All pathology specimens excised with MIP were positive histopathologically for parathyroid adenoma. The probable reason for these suspicious US positive, MIBI scan negative lesions were because of them being smaller lesions which decreases the sensitivity of MIBI scan. By the increased sensitivity of the combination localization technique, the intraoperative PTH assay was abandoned by clinicians to shorten the operation duration (23).

Dissection and exploration of 4 parathyroid glands with resection of abnormal parathyroid glands was the most appropriate treatment option. This method had a $95 \%$ success rate with an acceptable morbidity rate when done by the hands of an experienced parathyroid surgeon. However, surgeons who are less experienced in parathyroid surgery had 
higher morbidity rates and lower success rates for surgical treatment (<90\%) (24). MIP provides less experienced surgeons about parathyroidectomy to operate patients even with lower complication rates than bilaterally neck exploration.

Singh Ospina et al. compared bilaterally neck exploration with roll guided MIP (25). He found out that the treatment success of MIP is equal to bilaterally neck exploration and the complication rate of bilaterally neck exploration is higher than MIP. As a result, the use of ROLL which is technically safe and effective has become the new perspective for localizing parathyroid adenoma making the patient suitable for MIP. Thus, by the help of ROLL guided MIP, many general surgeons may successfully operate parathyroid adenomas.

ROLL is a safe procedure for patients and health professionals in the meaning of radiation. The injected dose for excised tissue and absorbed dose for closely related areas were measured by Cremonesi et al. All results were found to be safe and lower than the doses for other diagnostic examinations (26). Seven patients of the study group had previous neck operations. ROLL guided MIP was successfully applied to these patients safely and successfully. So we believe that MIP is also feasible for previously operated patients and recurrent disease.

To sum after the discussion above, MIP is a new, feasible technique with ROLL guidance. Although the sample size of our study is 45 and an uni-centered study. Bilateral neck exploration will probably be completely abandoned in the future decade except for extreme cases and MIP under ROLL guidance will be the gold standard for parathyroidectomy, especially for parathyroid adenomas.

In conclusion, we believe that ROLL-guided MIP is a feasible technique for parathyroid surgery, especially for parathyroid adenomas. It is a minimally invasive procedure that does not require exploration of the healthy tissue which reduces the complication rates. MIP reduces also surgeon-based failure and complications by standardizing the surgery. For these qualities, we think that ROLL guided MIP is superior to the classical approach for parathyroid adenomas.

\section{Conflict of interest}

The authors of the manuscript certify that they have NO affiliations with or involvement in any organization or entity with any financial interest (such as honoraria; educational grants; participation in speakers' bureaus; membership, employment, consultancies, stock ownership, or other equity interest; and expert testimony or patentlicensing arrangements), or non-financial interest (such as personal or professional relationships, affiliations, knowledge or beliefs) in the subject matter or materials discussed in this manuscript.

\section{References}

1. Mariani G, Gulec SA, Rubello D, Boni G, Puccini M, Pelizzo MR, Manca G, Casara D, Sotti G, Erba P, Voltterrani G, Giuiliano AE. Preoperative localization and radioguided parathyroid surgery. J Nucl Med. 2003; 44(9):1443-1458.

2. Miller BS, Dimick J, Wainess R, Burney RE. Age- and sexrelated incidence of surgically treated primary hyperparathyroidism. World J Surg. 2008; 32(5):795-799.

3. Marcocci C, Cetani F. Clinical practice. Primary hyperparathyroidism. N Engl J Med. 2011; 365(25):2389-2397.

4. Trolle W, Moller H, Bennedbaek FN, Nygaard B, Sorensen $\mathrm{CH}$. Minimally invasive surgery for hyperparathyroidism. Ugeskr Laeger. 2010; 172(1):33-38.

5. Malinvaud D, Potard G, Fortun C, Saraux A, Jezequel J, Marianowski R. Management of primary hyperthyroidism: toward minimal access surgery. Joint Bone Spine. 2004; 71(2):111-116.

6. Goldstein RE, Blevins L, Delbeke D, Martin WH. Effect of minimally invasive radioguided parathyroidectomy on efficacy, length of stay, and costs in the management of primary hyperparathyroidism. Ann Surg. 2000; 231(5):732-742.

7. Bergenfelz A, Lindblom P, Tibblin S, Westerdahl J. Unilateral versus bilateral neck exploration for primary hyperparathyroidism: a prospective randomized controlled trial. Ann Surg. 2002; 236(5):543-551.

8. Ben-Haim M, Zwas ST, Munz Y, Rosin D, Shabtai EL, Kuriansky J, Olchovsky D, Zmora O, Scarlat A, Ayalon A, Shabtai M. Focused, minimally invasive radio-guided parathyroidectomy: a feasible and safe option for elderly patients with primary hyperparathyroidism. Isr Med Assoc J. 2003; 5(5):326-328.

9. Walsh NJ, Sullivan BT, Duke WS, Terris D.J. Routine bilateral neck exploration and four-gland dissection remains unnecessary in modern parathyroid surgery. Laryngoscope Investig Otolaryngol. 2018; 4(1):188-192.

10. Cvasciuc IT, Ismail W, Lansdown M. Primary Hyperparathyroidism - Strategy for Multigland Disease in the Era of Spect-Ct. Acta Endocrinologica-Bucharest 2017; 13(1):1-6.

11. Tian Y, Miller JA. ASO Author Reflections: Imaging Strategies in Primary Hyperparathyroidism. Ann Surg Oncol. 2018; 25 (Suppl 3):860-861.

12. Cho E, Chang JM, Yoon SY, Lee GT, Ku YH, Kim HI, Lee MC, Lee GH, Kim MJ. Preoperative localization and intraoperative parathyroid hormone assay in Korean patients with primary hyperparathyroidism. Endocrinol Metab. 2014; 29(4):464-9.

13. Ilgan S, Ozturk E, Yildiz R, Emer O, Ayan A, Görgülü S, Alagöz E, Deveci S, Ozgüven MA, Tufan T.. Combination of preoperative ultrasonographic mapping and radioguided occult lesion localization in patients with locally recurrent/persistent papillary thyroid carcinoma: a practical method for central compartment reoperations. Clin Nucl Med. 2010; 35(11):847-852. 14. Terzioglu T, Senyurek YG, Tunca F, , Turkmen C, Mudun A, Salmasliogli A, Sanlı S, Bircan H, Demirkol O, Tezelman S. Excision efficiency of radioguided occult lesion localization in reoperative thyroid and parathyroid surgery. Thyroid. 2010;20(11):1271-1278. 15. Gatu A, Velicescu C, Grigorovici A, Danila R, Muntean V, Mogos SJ, Mogos V, Vulpoi C, Preda C, Branisteanu D. The volume of solitary parathyroid adenoma is related to preoperative Pth and 25Oh-D3, but not to calcium levels. Acta EndocrinologicaBucharest 2017;13(4):441-446.

16. Thind CR, Desmond S, Harris O, Nadeem R, Chagla LS, Audisio RA. Radio-guided localization of clinically occult breast lesions (ROLL): a DGH experience. Clin Radiol. 2005; 60(6):681686. 
17. Martinez AM, Sola M, de Tudela AP, Julian JF, Fraile M, Vizcaya S. Radioguided Localization of Nonpalpable Breast Cancer Lesions: Randomized Comparison With Wire Localization in Patients Undergoing Conservative Surgery and Sentinel Node Biopsy. Am J Roentgenol. 2009; 193(4):1001-1009.

18. Amza AB, Muntean V, Dindelegan G, Ciuce C, Georgescu CE. Surgery Outcomes in Patients with Secondary Hyperparathyroidism and Impact of Intra-Operative PTH Measurement. Acta Endocrinologica-Bucharest 2017; 13(3):322-328.

19. Adami S, Marcocci C, Gatti D. Epidemiology of primary hyperparathyroidism in Europe. J Bone Miner Res. 2002; 17 Suppl 2:N18-23.

20. Boi F, Lombardo C, Cocco MC, Piga M, Serra A, Lai ML, Calo PG, Nicolosi A, Mariotti S. Thyroid diseases cause mismatch between MIBI scan and neck ultrasound in the diagnosis of hyperfunctioning parathyroids: usefulness of FNA-PTH assay. Eur J Endocrinol. 2013;168(1):49-58.

21. Kao A, Shiau YC, Tsai SC, Wang JJ, Ho ST. Tc-99m methoxyisobutylisonitrile imaging for parathyroid adenoma: relationship to P-glycoprotein or multidrug resistance-related protein expression. Eur J Nucl Med Mol Imaging. 2002;29(8):10121015.
22. Cho E, Chang JM, Yoon SY, Lee GT, Ku YH, Kim HI, Lee MC, Lee GH, Kim MJ. Preoperative localization and intraoperative parathyroid hormone assay in Korean patients with primary hyperparathyroidism. Endocrinol Metab (Seoul). 2014;29(4):464469.

23. Barczynski M, Konturek A, Hubalewska-Dydejczyk A, Cichon S, Nowak W. Evaluation of Halle, Miami, Rome, and Vienna intraoperative iPTH assay criteria in guiding minimally invasive parathyroidectomy. Langenbecks Arch Surg. 2009; 394(5):843-849.

24. Norman J. Controversies in parathyroid surgery: The quest for a "mini" unilateral parathyroid operation seems to have gone too far. J Surg Oncol. 2012; 105(1):1-3.

25. Singh Ospina NM, Rodriguez-Gutierrez R, Maraka S, Espinosa de Ycaza AE, Jasim S, Castaneda-Guarderas A, Gionfriddo MR, Al Nofal A, Brito JP, Erwin P, Richards M, Wermers R, Montori VM. Outcomes of parathyroidectomy in patients with primary hyperparathyroidism: a systematic review and meta-analysis. World J Surg. 2016; 40(10):2359-2377.

26. Cremonesi M, Ferrari M, Sacco E, Rossi A, De Cicco C, Leonardi L, Chinol M, Luini A, Galimberti V, Tosi G, Veronesi U, Paganelli G. Radiation protection in radioguided surgery of breast cancer. Nucl Med Commun. 1999; 20(10):919-924. 